\title{
GAMBARAN LAMA PAJANAN DENGAN KADAR HbCO DALAM DARAH PADA PETUGAS RETRIBUSI TERMINAL PURABAYA BUNGURASIHSURABAYATAHUN 2015
}

\author{
Agustin Wulansari, Rachmaniyah, Imam Thohari
}

\section{ABSTRACT}

Bus station activity, transportation operations creates high pollution of carbon monoxide (CO) which is so dangerous for retribution officers of Purabaya bus station, Bungurasih. HbCO level can be affected by long exposure. This research aims to describe exposure to carbon monoxide tested through $\mathrm{HbCO}$ in the blood of retribution officers of Purabaya Bus Station Bungurasih.

This is a descriptive research with cross sectional approach and uses $x$ Blood Gas analyzer method. Sample of the research was 12 retribution officersworkingin morning and afternoon shift. Data was analyzed by descriptive tabulation in the form of table.Interview was conducted to determine characteristics of the retribution officers of Purabaya Bus station, Bungurasih.

Results showed that retribution officers possessed averageHbCO level of $11.94 \%$, exposure duration per day of $>8$ hours was $66.7 \%$ and $41.7 \%$ officers had smoking habit of $1 / 2-2$ packs/day.

It is concluded that HbCO level in officers blood washigher than normal level( $>5 \%)$. Improvement is needed in all aspects; all employees working outdoors are recommended to wear mass to filter gases or pollutants in which is harmful for health. They are recommended not to smoke when working. Manager of bus station also needsto do planting in bus station area.

Keywords: Bus station Retribution Officer, $\mathrm{HbCO}$ level, durationofexposure

\section{PENDAHULUAN}

Menurut Wicahyo (2010) Karbon monoksida (CO) adalahsenyawa yang sangat beracun, jenis gas tidakberwarna, tidakberbau,

taberasadapatterbakardanmudahmeledak, gas inilebihringandariudara.Kadar CO diperkotaan cukup bervariasi tergantung dari kepadatan kendaraan bermontor yang menggunakan bahan bakar bensin. Konsentrasi CO di udara per waktu dalam satu hari dipengaruhi oleh kesibukan atau aktivitas kendaraan bermotor yang ada. Faktor penting yang menentukan pengaruh CO terhadap tubuh manusia adalah konsentrasi $\mathrm{HbCO}$ yang terdapat di dalam darah, dimana semakin tinggi persentase hemoglobin yang terikat dalam bentuk $\mathrm{HbCO}$, semakin parah pengaruhnya terhadap kesehatan manusia.

Kadar $\mathrm{HbCO}$ dapat dipengaruhi oleh lama pajanan. Lama pajanan $\mathrm{CO}$, apabila semakin lama individu terpajan CO di tempat kerjanya akan meningkatkan pajanan $\mathrm{CO}$, sehingga kadar $\mathrm{CO}$ yang terikat $\mathrm{Hb}$ akan terakumulasi dalam darah semakin tinggi (Amang, 2011). Ini dapat menyebabkan penyakit yang kronis apabila terhirup terus menerus. Pajanan CO dari udara ambien dapat direfleksikan dalam bentuk kadar Haemoglobine Karbon Monoksida ( $\mathrm{HbCO}$ ) dalam darah.

Menurut Sujarwo (2014) bahwa pekerja yang terpajan oleh CO dan menderita arteri koroner akan lebih cepat mengalami hipoksia (kekurangan oksigen), lebih mudah mengalami serangan angina (nyeri dada), dan meningkatkan perasaan cemas walaupun dengan pajanan gas CO yang rendah. Efek CO pada aliran darah sangat beragam, efek yang sering muncul adalah denyut jantung dan tekanan darah rendah (hipotensi).

Beberapa individu dapat terpajan oleh CO karena lingkungan kerjanya.Salah satu tempat yang mempunyai kepadatan kendaraan yang tinggi di terminal adalah kawasan terminal Purabaya Bungurasih. Petugas retribusi menjadi pekerja non formal yang terpapar CO secara langsung karena keberadaan mereka yang setiap waktunya berada di teminal.

Penelitian ini bertujuan untuk menggambarkan pajanan karbon monoksida yang di uji melalui $\mathrm{HbCO}$ dalam darah pada petugas retribusi terminal Purabaya Bungurasih Surabaya.

\section{METODE PENELITIAN Jenis Penelitian}

Jenis penelitian yang digunakan adalah penelitian deskriptif. Bertujuan untuk menggambarkan kadar $\mathrm{HbCO}$ darah pada petugas retribusi di Terminal Purabaya Bungurasih Surabaya Tahun 2015. 


\section{Populasi dan Sampel}

Populasi dan sampel dalam penelitian ini adalah jumlah keseluruhan karyawan di terminal Purabaya Bungurasih sebanyak 12 petugas retribusi yang bekerja pada shift pagi mulai jam $06.00-14.00 \mathrm{dn}$ shift siang mulai jam $14.00-21.00$

\section{Teknik Pengumpulan Data}

Teknik pengumpulan data menggunakan lembar kuesioner dan wawancara.

\section{Teknik Analisis Data}

Setelah semua data-data terkumpul, kemudian diolah dengan menggunakan tabulasi. Selanjutnya dianalisis secara

deskriptif untuk menggambarkan kadar $\mathrm{HbCO}$ dalam darah pada petugas retribusi terminal Purabaya Surabaya Tahun 2015.

\section{HASIL PENELITIAN DAN PEMBAHASAN}

Pemeriksaan kadar HbCO sebanyak 12 sampel darah petugas retribusi di terminal yang terdiri dari 8 pos retribusi yang ada di terminal meliputi pos di tempat pemberangkatan bus antar kota, pos di tempat parkir mobil kendaraan pengantar / pribadi, pos di tempat parkir taxi / angguna.

\section{Hasil Kadar Hbco Dalam Darah Pada Petugas Retribusi Terminal Purabaya Bungurasih:}

TABEL 1

Hasil Pengukuran Kadar HbCO Tahun 2015

\begin{tabular}{|c|c|}
\hline Responden & Kadar HbCO (\%) \\
\hline R1 & 17,55 \\
\hline R2 & 10,14 \\
\hline R3 & 8,25 \\
\hline R4 & 12,46 \\
\hline R5 & 14,19 \\
\hline R6 & 14,08 \\
\hline R7 & 10,23 \\
\hline R8 & 9,24 \\
\hline R9 & 8,58 \\
\hline R10 & 10,29 \\
\hline R11 & 12,72 \\
\hline R12 & 15,57 \\
\hline
\end{tabular}

Sumber : data primer

Berdasarkan tabel 1, Petugas retribusi yang dijadikan sampel pengambilan darah pada shift pagi dan siang sebanyak 12 sampel, sampel tersebut diambil sekitar jam 10.30 - selesai oleh tim laboratorium poltekkes dan diperiksakan di Laboratorium Poltekkes kota Surabaya menggunakan metode Blood gas analizer.

Menurut Mukono (2011) dalam keadaan normal, konsentrasi CO di dalam darah berkisar antara 0,2\% sampai 1,0\% dan rata-rata sekitar 0,5\% CO.Dari hasil Laboratorium Poltekkes Surabaya, diperoleh kadar rata-rata $11,94 \%$ dan nilai kadar tertinggi $17,55 \%$ serta kadar terendah $8,25 \%$.

Menurut Fardiaz (2004) faktor penting yang menentukan pengaruh $\mathrm{CO}$ terhadap tubuh manusia adalah konsentrasi $\mathrm{HbCO}$ yang terdapat di dalam darah, dimana semakin tinggi presentase hemoglobin yang terikat dalam bentuk $\mathrm{HbCO}$, semakin parah pengaruhnyaterhadapkesehatanmanusia.

Konsentrasi $\mathrm{HbCO}$ di dalam darah dipengaruhi secara langsung oleh konsentrasi CO dari udara yang terhisap.

Pada konsentrasi CO tertentu di udara konsentrasi $\mathrm{HbCO}$ di dalam darah akan mencapai konsentrasi ekuilibrium setelah beberapa waktu tertentu. Konsentrasi ekuilibrium setelah beberapa waktu tertentu. Konsentrasi ekuilibrium $\mathrm{HbCO}$ tersebut akan tetap di pertahankan di dalam darah selama konsentrasi CO di dalam udara di sekelilingnya tetap tidak berubah. Akan tetapi $\mathrm{HbCO}$ secara perlahan-lahan akan berubah sesuai dengan perubahan konsentrasi CO di udara untuk mencapai ekuilibrium yang baru. Menurut Fardiaz (2004) Konsentrasi CO di udara per waktu dalam satu hari dipengaruhi oleh kesibukan atau aktivitas kendaraan bermotor yang ada. Semakin ramai kendaraan bermotor yang 
ada, semakin tinggi tingkat polusi $\mathrm{CO}$ di udara.Dalampengambilan data melalui wawancara terhadap petugas retribusi di Terminal Purabaya Bungurasih Surabaya didapatkan hasil beberapa keluhan yang dialami oleh petugas retibusi seperti pusing, mual, pandangankabur, lemas, dan lesu. Keluhan ini menunjukkan gejala klinis terpajan $\mathrm{CO}$ yang cukup tinggi.

Menurut Mukono (2011) harga normal dari karbon monoksida dalam darah sekitar 0,5 persen. Kadar ini akan meningkat apabila seseorang menderita sakit. Gas

oksigen dan karbon monoksida akan ditarik oleh zat besi dalam hemoglobin dan hemoglobin ini mempunyai daya ikat yang besar terhadap karbon monoksida. Apabila udara mengandung $\mathrm{CO}$ sebesar 30 ppm, maka besarnya CO dalam darah sekitar 5 persen. Ini akan tetap dipertahankan sebesar $5 \%$ terus, jika frekuensi pernapasan dan kadar CO di atmosfer tidak berubah.

\section{Menggambaran kadar HbCO dalam darah terhadap lama pajanan :}

TABEL 2

Gambaran Lama Pajanan Dengan Kadar Hbco Pada Petugas Retribusi Terminal Purabaya Bungurasih Tahun 2015

\begin{tabular}{|c|c|c|c|c|c|c|}
\hline \multirow{2}{*}{ Kadar HbCo (\%) } & \multicolumn{3}{|c|}{ Lama pemajanan } & \multicolumn{2}{c|}{ Jumlah } \\
\cline { 2 - 6 } & \multicolumn{4}{|c|}{$\leq$ jam per hari } & $>8$ jam per hari & \multicolumn{2}{c|}{} \\
\cline { 2 - 7 } & $\mathrm{N}$ & $\%$ & $\mathrm{~N}$ & $\%$ & $\mathrm{~N}$ & $\%$ \\
\hline$\leq 5$ & 0 & 0 & 0 & 0 & 0 & 0 \\
\hline$>5$ & 4 & 33,3 & 8 & 66,7 & 12 & 100 \\
\hline Total & 4 & 33,3 & 8 & 66,7 & 12 & 100 \\
\hline
\end{tabular}

Sumber : data primer

Berdasarkan tabel 2, menggambarkan lama pajanan mempengaruhi kadar $\mathrm{HbCO}$ sehingga kadar $\mathrm{HbCO}$ akan meninggkat > 5\%. Menurut Ervisa (2013) Pemajanan CO dari udara ambien dapat direfleksikan dalam bentuk kadar karboksi-haemoglobin ( $\mathrm{HbCO}$ ) dalam darah yang terbentuk dengan sangat pelahan karena butuh waktu 4-12 jam untuk tercapainya keseimbangan antara kadar CO di udara dan $\mathrm{HbCO}$ dalam darah. Oleh karena itu kadar CO didalam lingkungan, cenderung dinyatakan sebagai kadar ratarata dalam 8 jam pemajanan Data CO yang dinyatakan dalam rata-rata setiap 8 jam pengukuran sepajang hari (moving 8 hour average concentration) adalah lebih baik dibandingkan dari data CO yang dinyatakan dalam rata-rata dari 3 kali pengukuran pada periode waktu 8 jam yang berbeda dalam sehari. Perhitungan tersebut akan lebih mendekati gambaran dari respons tubuh manusia terhadap keracunan CO dari udara. Sehingga petugas retribusi terminal semakin lama terpajan oleh gas karbon monoksida yang dihasikan oleh asap kedaraan akan semakin meningkatnya kadar $\mathrm{HbCO}$ dalam darah. Menurut fardiaz (2004) Kadar HbCO dalam darah $>5 \%$ akan mempengaruhi kesehatan seperti jantung dan pulmonari. Oleh kerena itu petugas retibusi di terminal purabaya sebaiknya bekerja memakai masker supaya menghindari gas karbon monoksida masuk ke dalam tubuh dan kawasan di terminal untuk menanam tanaman untuk mengurangi kadar $\mathrm{CO}$ di udara

\section{Menggambaran kadar HbCO dalam darah Dengan kebiasaan merokok:}

TABEL 3

Gambaran Kebiasaan Merokok Dengan Kadar Hbco Pada Petugas Retribusi Terminal Purabaya Bungurasih Tahun 2015

\begin{tabular}{|c|c|c|c|c|c|c|c|c|c|c|}
\hline \multirow{3}{*}{ Kadar HbCo (\%) } & \multicolumn{8}{|c|}{ Kebiasaan Merokok } & & \\
\hline & \multicolumn{2}{|c|}{$\begin{array}{c}0 \text { batang per } \\
\text { hari (tidak } \\
\text { merokok) }\end{array}$} & \multicolumn{2}{|c|}{$\begin{array}{c}\leq 1 / 2 \\
\text { pak/hari } \\
\text { (ringan) }\end{array}$} & \multicolumn{2}{|c|}{$\begin{array}{c}1 / 2 \text { - } 2 \text { pak/hari } \\
\text { (sedang) }\end{array}$} & \multicolumn{2}{|c|}{$\begin{array}{c}>2 \text { pak/hari } \\
\text { (berat) }\end{array}$} & \multicolumn{2}{|c|}{ Jumlah } \\
\hline & $\mathrm{N}$ & $\%$ & $\mathrm{~N}$ & $\%$ & $\mathrm{~N}$ & $\%$ & $\mathrm{~N}$ & $\%$ & $\mathrm{~N}$ & $\%$ \\
\hline$\leq 5$ & 0 & 0 & 0 & 0 & 0 & 0 & 0 & 0 & 0 & 0 \\
\hline$>5$ & 2 & 16,7 & 3 & 25,0 & 5 & 41,7 & 2 & 16,7 & 12 & 100 \\
\hline Total & 2 & 16,7 & 3 & 25,0 & 5 & 41,7 & 2 & 16,7 & 12 & 100 \\
\hline
\end{tabular}

Sumber : data primer 
Berdasarkan tabel 3, menggambarkan keseluruhan petugas retribusi memiliki kebiasaan merokok, tetapi hanya 2 orang yang tidak merokok memiliki kadar $\mathrm{HbCO}>$ $5 \%$ sebanyak 16,7\%. Menurut Fardiaz (2004) katagori tidak merokok median ekuilibrium $\mathrm{HbCO}$ di dalam darah 1,3\% tetapi rata-rata petugas retribusi tidak merokok kadar $\mathrm{HbCO} 8,35 \%$ yang artinya kadar $\mathrm{HbCO}>5 \%$ atau diatas normal, kemungkinan petugas tidak merokok kadar $\mathrm{HbCO}>5 \%$ di akibatkan dari asap rokok yang mempengaruhi kadar $\mathrm{HbCO}$ meningkat.

Menurut Mukono (2011) bahwa kadar CO yang berasal dari asap rokok sekitar 400 dan 475 ppm. Sebesar 54\% gas CO yang diisap oleh perokok masuk ke dalam peredaran darah. Efek karbonmonoksida terhadap penglihatan, apabila kadar $\mathrm{HbCO}$ meningkat sampai $5 \%$, maka seseorang tidak dapat melihat dengan jelas, lebih-lebih dalam keadaan remangremang. Rokok dapat menyebabkan penurunan kepekaan mata terhadap sinar. Apabila rokok tidak mengandung nikotin, maka tidak memengaruhi kepekaan mata terhadap sinar. Dari sini dapat disimpulkan bahwa nikotin dapat mengurangi penglihatan.

Untuk itu petugas retribusi diharapkan tidak membiasakan merokok saat bekerja, supaya asap rokok tidak mengganggu kesehatan petugas retribusi yang lain.

\section{KESIMPULAN}

Berdasarkan hasil penelitian dan analisis data dapat disimpulkan sebagai berikut :

1. Kadar $\mathrm{HbCO}$ dalam darah pada petugas retribusi terminal Purabaya Bungurasih keseluruhan $>5 \%$ di atas normal.

2. Menggambarkan lama pemajanan $>8$ jam per hari sebanyak $66,7 \%$ dan $\leq 8$ jam per hari sebanyak 33,3\%. Dari keseluruhan petugas retribusi memiliki kadar $\mathrm{HbCO}>5 \%$ sebanyak $100 \%$.

3. Menggambarkan kebiasaan merokok sebanyak $83,4 \%$ dan tidak merokok nilai rata-rata $8,35 \%$. Dari keseluruhan petugas retribusi memiliki kadar $\mathrm{HbCO}$ $>5 \%$ sebanyak $100 \%$.

\section{SARAN}

1. Bagi kepala Terminal Purabaya Bungurasih diharapkan semua karyawan yang bekerja di luar ruangan memakai masker untuk menyaring gasgas atau cemaran di udara yang membahayakan kesehatan.

2. Bagi karyawan di terminal khususnya petugas retribusi sebaiknya tidak membiasakan merokok saat bekerja.

3. Bagi semua pekerja yang ada di terminal diharapkan menjaga kesehatannya dengan makanan yang bergizi dan sering berolahraga agar dapat menghirup udara segar kaya oksigen yang mengganti kadar CO dalam darah.

4. Bagi pengelola Terminal Purabaya sebaiknya menambah tanaman di kawasan terminal untuk mengurangi kadar CO di udara.

\section{DAFTAR PUSTAKA}

Fardiaz, Srikandi. 2004. Polusi Air danUdara.Bogor. Kanisius.

Khoirot, Asisul. 2010. KarbonMonoksida. Malang. Penebarswadaya.

Mahditiara, Ervisa. 2013. Parameter PencemaranUdaraKarbonMonoksid a.Makassar. Salembateknika.

Mukono.

2011. AspekKesehatanPencemaranUdara - Surabaya. UniversitasAirlangga (AUP).

Notoatmodjo, Soekidjo. 2010. MetodologiPenelitianKesehatan. Jakarta. PT RinekaCipta.

Nurbiantara, Setiyawan. 2010. PengaruhPolusildara TerhadapFungsiParuPadaPolisiLalu Lintas. Surakarta. ANDI.

Purabaya, 2015. https://purabayabusterminal.word press.com/profil/.14 Febuari 2015.

Putut, Endrayana., dan Widodo, Basuki. 2011. Simulasi Model DispersiPolutanKarbonMonoksida di PintuMasukMasukTol. http://digilib.its.ac.id/public/ITSMaster-18907-Paper-420703.pdf. 16 Februari 2015.

Radytia, Jevon. 2011. Pengaruh Volume KendaraanterhadapKosentrasiPenc emaran NOx padaUdara Ambien di PintuTol.Depok.http://lib.ui.ac.id/fi le?file=digital/20291490-S1337Jevon\%20Radytia.pdf. 10 Januari 2015.

Ruhiat, Tedi. 2006. Polusildara. Jakarta. Citra CiptaPurwosari.

Sari. 2013. Analisa Kadar CO. Padang. PT AgroMediaPustaka.

Standar Nasional Indonesia 19-0232-2005 tentangNilaiAmbang Batas (NAB) zatkimia di udaratempatkerja.

Sugiyono. 2011. MetodePenelitianKuantitatif, Kualitatifdan R \& D. Bandung :Alfabeta.

Undang-UndangRepublik Indonesia Nomor $32 \quad$ Tahun 2009 TentangPerlindungan Dan PengelolaanLingkunganHidup.Wic ahyo, Yuli. 2010. encemaranUdara.Bandung. CiptaKarya. 